\title{
Improving Ion Beam Injector Performance by Augmenting Capacitance of Vacuum Diode
}

\author{
David A. Goerz \\ Michael J. Wilson
}

This paper was prepared for submittal to the 1998 23rd International Power Modulator Symposium

Rancho Mirage, CA

June 22-25, 1998

June 24, 1998

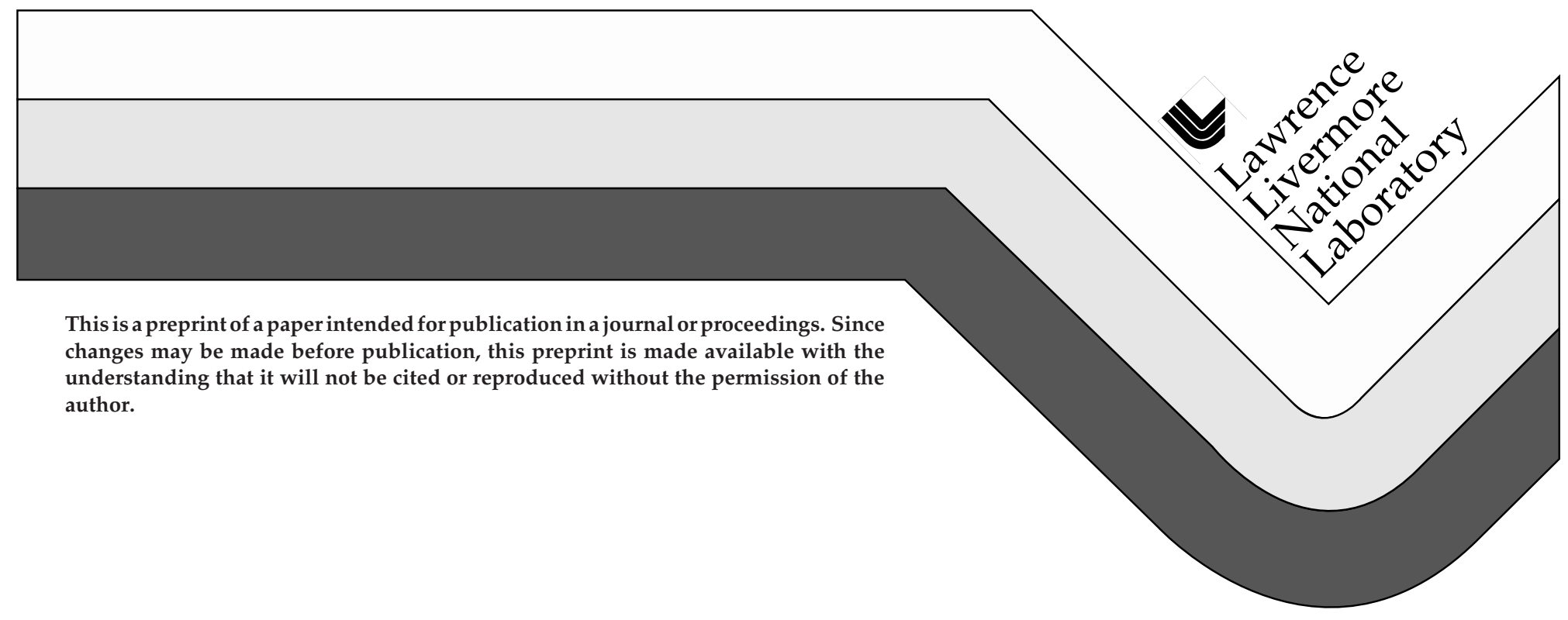




\section{DISCLAIMER}

This document was prepared as an account of work sponsored by an agency of the United States Government. Neither the United States Government nor the University of California nor any of their employees, makes any warranty, express or implied, or assumes any legal liability or responsibility for the accuracy, completeness, or usefulness of any information, apparatus, product, or process

disclosed, or represents that its use would not infringe privately owned rights. Reference herein to any specific commercial product, process, or service by trade name, trademark, manufacturer, or otherwise, does not necessarily constitute or imply its endorsement, recommendation, or favoring by the United States Government or the University of California. The views and opinions of authors expressed herein do not necessarily state or reflect those of the United States Government or the University of California, and shall not be used for advertising or product endorsement purposes. 


\title{
Improving Ion Beam Injector Performance by Augmenting Capacitance of Vacuum Diode
}

\author{
David A. Goerz and Michael J. Wilson \\ Lawrence Livermore National Laboratory \\ Livermore, California 94550-9900
}

\begin{abstract}
The recirculating induction accelerator is a new class of particle accelerator being developed at LLNL as a reduced-cost driver for heavy-ion beam driven inertial fusion energy. Ongoing research and development of advanced beam control technologies for the recirculator system requires a very stable and reproducible ion beam source. The injector pulse modulator must be capable of producing very precise high-voltage pulses in order to reduce the current modulation instability and achieve the required beam reproducibility. Computer modeled simulations of beam dynamics have established that errors greater than 0.1 percent in the flatness of the $120 \mathrm{kV}$ injector pulse can create intolerable energy deviations. The pulse modulator that was developed to satisfy the stringent requirements is described in the accompanying paper by Wilson [1]. A crucial aspect of the overall solution is a modification made to the vacuum diode apparatus, whereby high-voltage capacitors were added in close proximity to the thermionic potassium-ion emitter. This paper discusses the rationale for augmenting the normally small capacitance of the injector diode, and presents design information, including an illustrated layout, electrostatic field modeling results, and data on ceramic capacitors operating at elevated levels.
\end{abstract}

\section{BACKGROUND}

Recirculating heavy-ion induction accelerators (recirculators) are being considered as low-cost drivers for inertial-fusion-energy (IFE) power plants [2] In the U.S., a program of theoretical and experimental investigations is underway to explore the most important aspects of heavy-ion-fusion (HIF) driver physics and technology $[3,4]$. At LLNL, exploratory research and development sponsored by LLNL's Engineering Directorate is focused on developing a set of enabling technologies for advanced accelerators [5].

\section{INTRODUCTION}

Ongoing research and development of advanced beam control technologies for the heavy-ion recirculator system requires a very stable and reproducible ion-beam source. The injector pulse modulator must be capable of producing very precise high-voltage pulses in order to reduce the current modulation instability and achieve the required beam reproducibility [6].

During initial experiments on LLNL's small-scale recirculator, measurements were obtained that indicated the voltage waveform of the diode pulser had a ripple of approximately $\pm 1.3 \%$ of the $65-\mathrm{kV}$ flattop voltage, and the beam current had a larger corresponding ripple of approximately $\pm 8.4 \%$ of the 1.5-mA average current at the location of a Faraday cup, approximately $1.9 \mathrm{~m}$ downstream from the ion source. Subsequent simulations by Barnard [7] corroborated the physical nature of these observations, and it was determined that such large perturbations would pose serious consequences in the beam transport through the recirculator. This drove the requirement to come up with an improved pulser for the ion injector.

\section{IMPULSER}

The injector pulser that was developed to satisfy the rather stringent requirements is described in the accompanying paper by Wilson [1], and in an internal LLNL report [8]. It is basically a lowimpedance, high-energy capacitor discharge unit (CDU) employing spark gap switches to turn on and crowbar the output. The output level is adjustable from 60 to $120 \mathrm{kV}$, and the unit can be repetitively operated at $1 \mathrm{~Hz}$. The proper risetime and fallime is obtained by changing series and shunt components in the circuit.

A critical aspect of the implementation is to modify the electrical characteristics of the vacuum diode region of the ion source itself. By adding discrete $\mathrm{HV}$ capacitors in this region, the nominally $100 \mathrm{pF}$

\footnotetext{
* Work performed under the auspices of the U. S. Department of Energy by the Lawrence Livermore National Laboratory under Contract W-7405-Eng-48.
} 
capacitance of the ion diode is increased to approximately $10 \mathrm{nF}$, depending on the number of additional capacitors installed. Then, the combination of pulser series resistance and augmented diode capacitance predominantly determines the voltage risetime at the diode.

\section{DIODE}

The ion injector in LLNL's small-scale recirculator is a typical design that uses a thermionic, potassiumdispenser source. The filament heated dispenser cup sits within a short graphite cylinder with a frustum shaped contour along the surface facing the front plate that has an aperture through which the ion beam is extracted. The thermionic emitter assembly is attached by an alignment mechanism to a metal mounting plate that is supported from the grounded front plate with machinable ceramic standoffs. A positive high-voltage pulse applied to the thermionic ion source accelerates potassium ions toward the front plate and through the aperture. Figure 1 depicts the basic layout and shows results of electrostatic field modeling. The lines shown between the graphite/emitter and the front plate are equipotential lines. This plot also shows the rather large space between the graphite and the chamber wall.

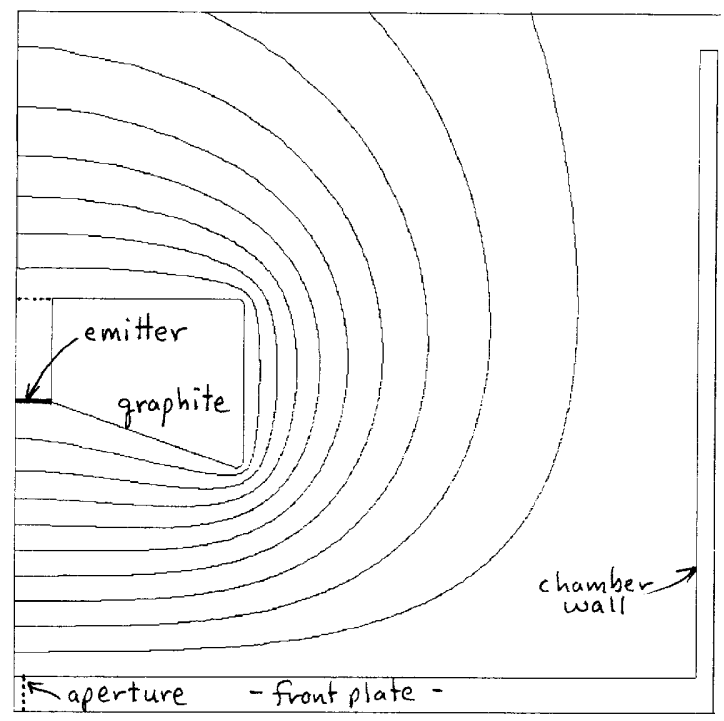

Figure 1. Basic layout of the thermionic source showing equipotential lines from electrostatic field modeling of the diode region before modifications.

The existing diode assembly was retrofitted to add discrete capacitors that would augment the limited capacitance of the diode itself. We selected Murata 3-nF, 40-kV, N4700 ceramic capacitors for this application. While only rated at $40 \mathrm{kV}$, we have experience operating these components reliably at higher levels [9], and chose to rely on two capacitors in series to satisfy the $120 \mathrm{kV}$ operating level requirement. Figure 2 is a line drawing of the thermionic source assembly and its mounting hardware along with multiple pairs of ceramic capacitors that were installed in a circular pattern around the thermionic ion source.

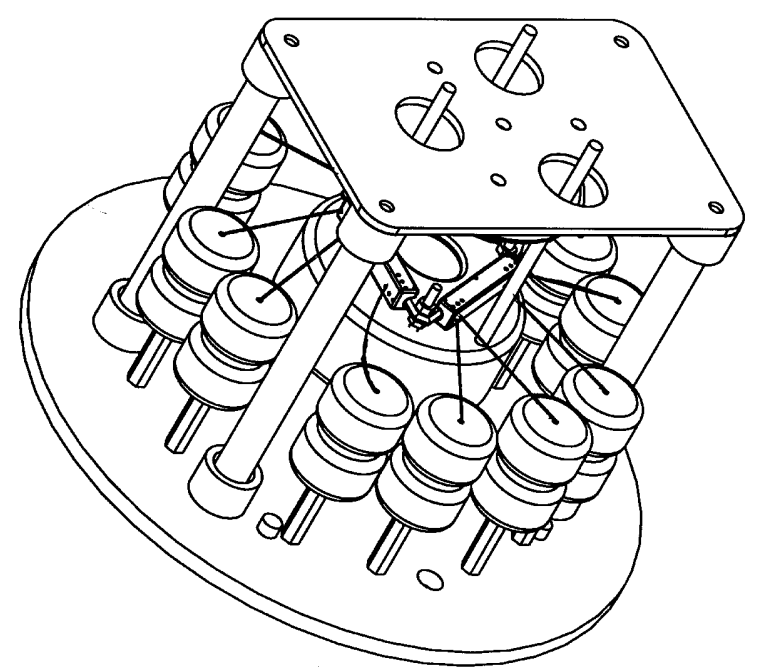

Figure 2. Drawing of thermionic source and its mounting hardware along with multiple pairs of ceramic capacitors installed in a circular pattern around the ion source.

Placement of the ceramic capacitors depended on several important factors, and many options were considered before a final implementation was decided. High voltage holdoff was the most critical concern. Figure 3 illustrates one of the mounting positions that was evaluated. It is apparent from examining this plot of equipotential lines that the electric field stress is rather high between the edge of the graphite and the bottom side of the lower capacitor which would be at ground potential.

Mounting the capacitors closer to the front plate, as illustrated in Figure 4, reduces the electrical stress at the lower edge of the graphite, and provides a more uniform field in the diode region. This is the position that was selected for the augmenting capacitors.

Another concern was the heat load from the 920-C thermionic emitter, should the capacitors be in a direct line of sight. A quick analysis of the thermal loading indicated there would not be a serious problem for the chosen position. 


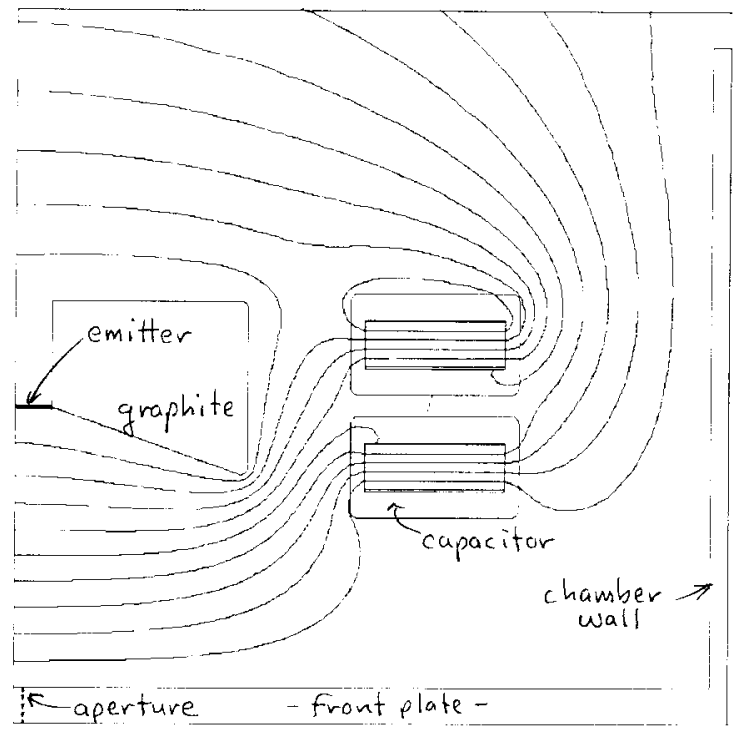

Figure 3. Equipotential lines around the diode region with adjacent capacitors. Note the rather high electric field stress near the edge of the graphite.

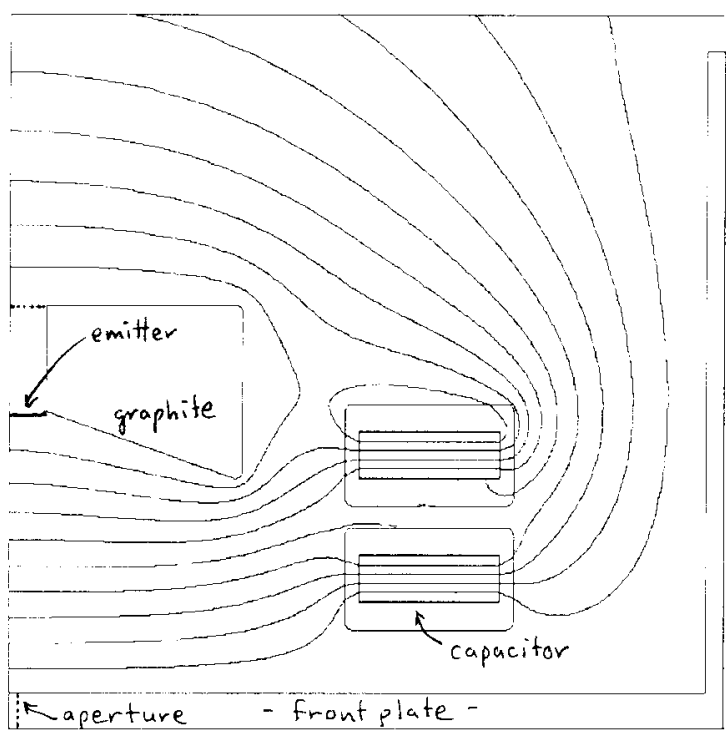

Figure 4. The result of lowering the capacitors and a slight decrease in relative field strength in the diode region.

A view of the diode region through a side port is shown in Figure 5. The design requirements for the impulser as reported in the accompanying paper do not require a high-fidelity circuit layout or a low inductance configuration. This allows as shown bare conductors to be used for the connection to the cathode with minimal effect on the injector performance.

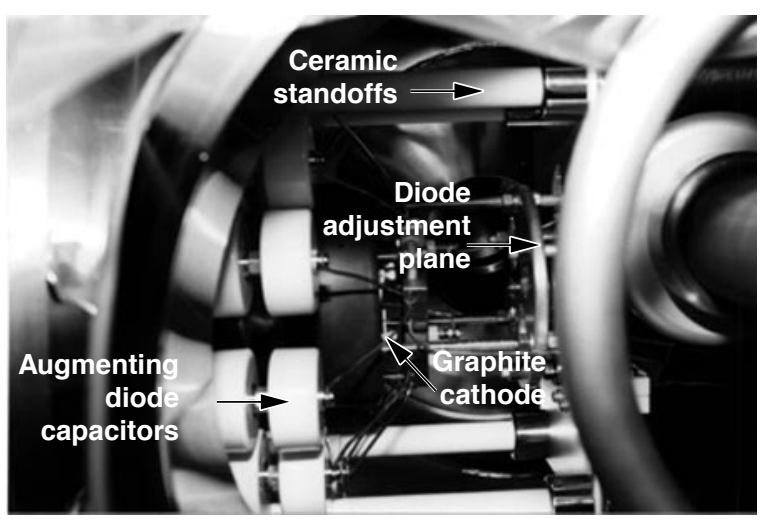

Figure 5. The modified diode as seen from an open side port. Ceramic capacitors are fitted around the ion source to augment the capacitance of the diode region.

Figure 6 shows the diode region as viewed from the impulser. The initial impulser adjustments are made by measuring the diode voltage at levels up to $30-\mathrm{kV}$ in air. Also shown in Figure 6 is a highvoltage probe connecting to the diode from a side port used to measure the diode impulse voltage profile.

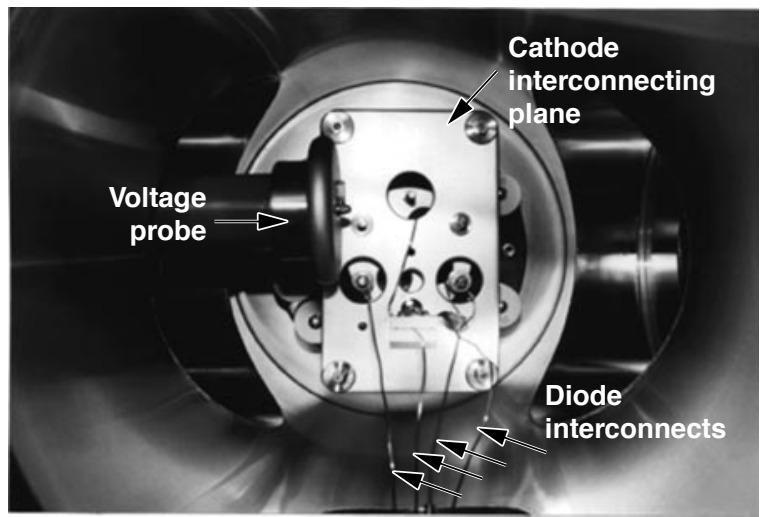

Figure 6. A rear-view of the diode region. Connections to the ion source for filament current and HV pulses are made with four No. 12 AWG bare, solid copper wire.

\section{CAPACITORS}

The Murata 3-nF, 40-kV, N4700-type ceramic capacitors chosen for this application have a nominal dielectric constant of 2600 . The manufacture indicates they will change in capacitance less than 2 percent over the rated operating voltage. The design parameters of our circuit requires that these components operate to levels of $60 \mathrm{kV}$, or 150 percent of their rated voltage. A measurement of the dielectric constant at the intended operating level was performed to ensure that the true values of the components were known. A process to quantify the dielectric constant as a function of average field-stress has 
been developed and used for this purpose [10]. Figure 7 represents a 3-nF capacitor biased to 90$\mathrm{kV}$ and the resulting dielectric constant as a function of average field-stress across the device under test. For this application, the upper operating level for an individual capacitor is $60 \mathrm{kV}$, and the nominal field stress in the capacitor material will be $40 \mathrm{kV} / \mathrm{cm}$. Operating at this stress level reduces the capacitance value by 29 percent. This capacitance reduction results in a dynamic impedance change of the diode of 118 percent. The significance of the diode impedance on the operation of the injector is discussed in the paper by Wilson [1].

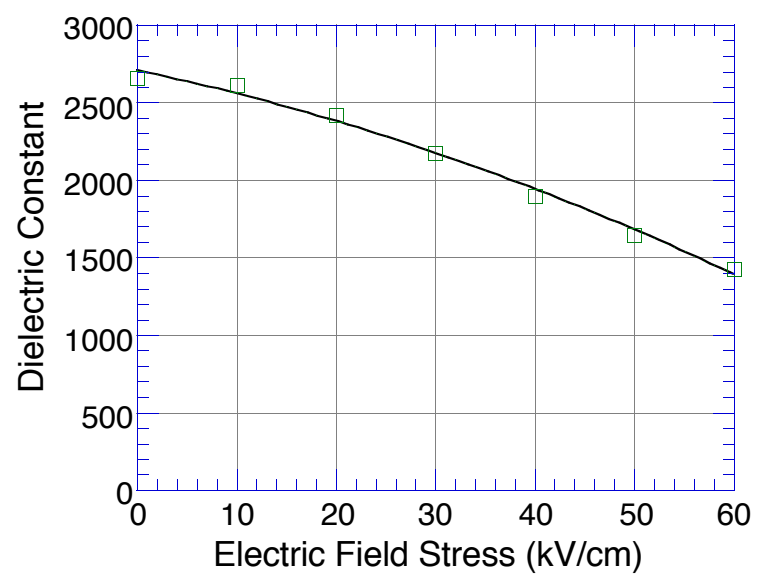

Figure 7. Dielectric constant verses electric field stress for Murata 3-nF, 40-kV, N4700-type ceramic capacitors.

\section{CONCLUSIONS}

Performance of ion-injectors can be improved when system-level, integrated designs take into account the possibility of modifying the load characteristics. By augmenting the capacitance of the vacuum diode assembly, a simple CDU-type $\mathrm{HV}$ pulser was implemented to provide the specific risetime and stringent flatness requirements needed to perform critical experiments on LLNL's HIF recirculator. The modifications described here were proven successful over the past year of experimental operations.

\section{REFERENCES}

[1] M. Wilson, D. Goerz, and R. Speer "An Elegant Impulser Developed for Flat Beam Injection," in The 1998, 23rd International Power Modulator Symposium; Rancho Mirage, California, USA; June 22-25, 1998.

[2] J. Barnard, et. al., "Recirculating Induction Accelerators for Heavy Ion Fusion," in The Proceedings of the International Symposium on Heavy Ion Inertial Fusion, Frascati, Italy, May 25-28, 1993.

[3] A. Friedman, et. al., "Progress Toward a Prototype Recirculating Induction Accelerator for Heavy-Ion Fusion," in The Proceedings of the IEEE 1995 Particle Accelerator Conference, Dallas, TX, May 1-5, 1995.

[4] C. Sangster et. Al., "Status of LLNL Experiments in Bending and Recirculating," presented at The PAC97 Meeting of the American Physical Society, UCRL-JC126544.

[5] M. Hernandez, et. al., "Technologies for Advanced Induction Accelerators," Project ID 97-ERD-086, LDRD Annual Report FY 1997, Lawrence Livermore National Laboratory, UCRL-LR-113717-97.

[6] John Barnard, private communication, LLNL internal memo "Waveform for Injector Pulser," HIF Note No. 954, July 6, 1995.

[7] John Barnard, private communication, LLNL internal memo "Implications of Pulser Voltage Ripple," HIF Note No. 96-12, September 24, 1996.

[8] M. Wilson, D. Goerz, and R. Speer, Heavy Ion Fusion (HIF) Impulse Injector Design, Construction, and Checkout, Lawrence Livermore National Laboratory, UCRL-ID-130764, May 1998.

[9] D. Goerz, M. Wilson, and R. Speer, "A Low-Profile High-Voltage Compact Gas Switch," in The 11th IEEE International Pulsed Power Conference, Baltimore, MD, July 1997.

[10] M. Wilson, D. Goerz, and R. Speer, LCR Bridge Measurements at Elevated Operating Levels, Lawrence Livermore National Laboratory, UCRL-ID-125796, December 1997. 


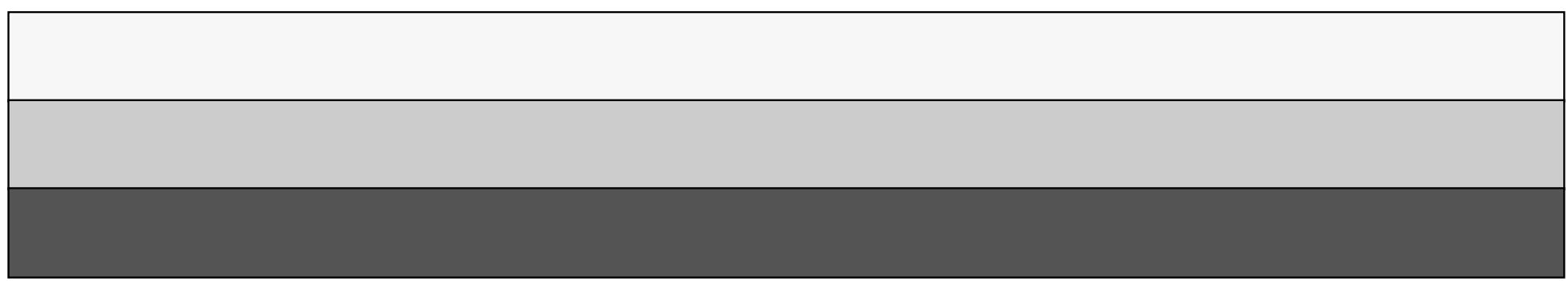

